\title{
Comparative Study between Multislice Computed Tomography Coronary Angiography and Invasive Coronary Angiography in Diagnosis of Mid and Distal Segment Coronary Artery Stenosis
}

\author{
SALAH EL-DIN I. AGAMY, M.Sc.; MAI M. SALAMA, M.D.; AYMAN M. EL-SAEED, M.D. and \\ AMR A. MUBARAK, M.D. \\ The Department of Cardiovascular Medicine, Faculty of Medicine, Tanta University
}

\begin{abstract}
Background: Computed Tomography Coronary Angiography (CCTA) is a promising method for detection and exclusion of obstructive coronary artery stenosis. Mid and distal segments of coronary arteries were chosen because they are usually small in caliber especially distal segment (usually less than $1.5 \mathrm{~mm}$ ) and they are affected by cardiac motion on the contrary, the proximal segment is always away from the myocardium and usually larger in diameter so that it can be easily diagnosed by CCTA.

Objective: The purpose of this study was to evaluate the added value of CT coronary angiography for detecting Coronary Artery Disease (CAD) in mid and distal segment lesions using invasive coronary angiography as a reference standard.

Methods: We prospectively evaluated 20 patients who suspected to have CAD and underwent CTA. we assessed mid and distal segment lesions using invasive coronary angiography as a reference standard. We excluded proximal segment lesion, high calcium score (800), arrhythmias, post percutaneous coronary intervention and post coronary artery bypass graft.

Results: A total of 20 subjects underwent both CCTA and ICA ( $60 \%$ were females with mean age: 58.1 years). On a patient based model, the sensitivity, specificity, and positive and negative predictive values to detect mid segment lesions were $88.9 \%, 95.2 \%, 88.9 \%$, and $95.2 \%$ respectively and for distal lesions were $85 \%, 100 \%, 100 \%, 98.1 \%$, respectively. Diagnosis of mid and distal segment lesions by both CT and coronary angiography showed statistically significant strong positive correlation.

Conclusion: CT angiography is a reliable tool and has high accuracy for detection of CAD in both mid and distal segment lesions. Importantly, the high NPV (97\%) firmly establishes CCTA as an effective noninvasive method to rule out obstructive coronary artery stenosis in patient with moderate pre-test probability.
\end{abstract}

Key Words: CT coronary angiography - Invasive coronary angiography - Calcium score.

Correspondence to: Dr. Salah El-Din I. Agamy,

The Department of Cardiovascular Medicine,

Faculty of Medicine, Tanta University

\section{Introduction}

CONVENTIONAL coronary angiography has been considered the gold standard method for diagnosis coronary lesions. However, coronary angiography is unlikely to be accepted in the absence of significant lesions and risk of complications due to its invasive features. Therefore, an alternative noninvasive procedure for detection of Coronary Artery Disease (CAD) is necessary [1]

Coronary Computed Tomography Angiography (CCTA) is unique in its ability to noninvasively diagnose $\mathrm{CAD}$ and to accurately detect significant stenosis plus it is a quick and relatively simple procedure that can be performed within 10 to 20 minutes [2].

Many researchers have used multi-slice CT coronary angiography to diagnose coronary artery stenosis using invasive coronary angiography as a standard of reference. However, great variations in sensitivity, specificity, and diagnostic accuracy exist [3].

Despite high negative predictive value, factors such as high heart rate, arrhythmia, obesity, and high coronary calcium levels continue to limit the overall evaluability and positive predictive value of coronary $\mathrm{CT}$ angiography $[4,5]$.

\section{Patients and Methods}

This prospective study was conducted at The Department of Cardiovascular Medicine and Department of Radiology, Tanta University Hospital and Tanta University Educational International Hospital during the period between July 2016 and July 2017 and included 20 patients with coronary artery disease. 
The enrolled patient met all of these criteria:

1- Patients suspected to have coronary artery disease.

2- Different degree of coronary stenosis that was found through CT coronary angiography in mid and distal segments.

\section{Exclusion criteria were:}

1- Heart rate greater than 70 beats per minute.

2- Arrhythmia.

3- Orthopnea.

4- High coronary calcium score (more than 800).

5- Renal impairment (Creatinine level $>1.5 \mathrm{mg} / \mathrm{dl}$ ).

6- Contrast allergy.

7- Pregnancy.

8- Past history of PCI including stenting.

9- Past history of CABG.

10- Inability to hold breath for about 10 seconds.

11- Acute coronary syndrome one month before CT examination.

12- Proximal coronary segment lesion detected by CTA or coronary angiography.

All included patients were subjected to detailed history taking, clinical examination including measurement of vital signs, ECG, echocardiography and laboratory investigations including kidney function test.

CT coronary angiography examination: $320-$ row CT scanner (Aquilion one system, Toshiba Medical Systems, Tokyo, Japan) was used to exam the studied patients. Multislice CT coronary angiography was done for all patients.

\section{Instructions to the patients:}

- No food 3 or 4 hours before examination.

- No caffeine or smoking 12 hours before examination.

- Encourage water intake.

- Avoid exercise at the day of examination.

- Avoid smoking.

- Take all regular medications.

- Take premedications for contrast allergy as needed.

- Take premedications for renal protection as needed.

- Sildenafil should be avoided for $48 \mathrm{~h}$ before the scan.

- Stop Metformin 48h after the scan.
In patients with a resting heart rate of 65 beats per minute or more before the scan, metoprolol was administered orally $50 \mathrm{mg}$ one hour before the scan to achieve a target heart rate of less than or equal to 65 beats per minute [6]. Additional 50mg of metoprolol was given after 60 minutes for patients with inadequate heart rate control. To those with contraindication to B-blockers we gave Ivabradine $5 \mathrm{mg}$ orally one hour before the scan [6].

Breath holding test was performed to avoid respiratory motion artifacts as well as $5 \mathrm{mg}$ sublingual Isosorbid dinitrates was given.

Non-ionic contrast media (Ultravist $370 \mathrm{mg}$ I/mL; Bayer HealthCare, Berlin, Germany) was injected through IV line using a dual-head powered automatic injector. The patients received a 60$90 \mathrm{~mL}$ bolus of contrast medium at an infusion rate of $5 \mathrm{~mL} / \mathrm{sec}$, followed by $50 \mathrm{~mL}$ of saline solution. The scan was performed according to the bolustracking technique.

A CCTA examination was usually an anteriorposterior scout topogram that allowed the technicians to accurately prescribe the scanned field of view (sFOV). The upper limit of the sFOV was just below the carina. The caudal limit of the sFOV should have been slightly below the diaphragm to include cardiac apex then usually the non-contrasted scan for calcium scoring. Patients with calcium score more than 800 were excluded.

Acquisition parameters: 0.35 second gantry rotation time, variable $\mathrm{mA}$ according to patient body habitus (range: $100-135 \mathrm{Kv}$ ).

Prospective ECG gating was used with volume scanning method. Single heart beat acquisition was routinely performed with heart rate below $65 \mathrm{bpm}$ and the scan window was set at $70-80 \%$ of RR interval while 2 heart beat acquisition was performed in patient with heart rate above $70 \mathrm{bpm}$. When heart rate between 65 and 70bpm, the scanning window was set to $30-80 \%$ of RR interval to include end systolic phase.

Images were reconstructed at a slice thickness of $0.5 \mathrm{~mm}$ and $0.5 \mathrm{~mm}$ interval with smooth and sharp reconstruction kernels.

The reconstructed images were transferred to workstation (Vitrea Fx, vital images, USA) to obtain multiplanar images in axial, sagittal and coronal planes. Also Maximum intensity projections, 3D Volume rendering technique and Curved Multiplanar Reconstruction were obtained. 
Image analysis: The causes of impaired image quality were classified as blooming artifacts generated by large calcifications, motion artifacts related to noncompliance with breath holding, cardiac motion artifact related to sudden increase of heart rate, or impaired contrast to-noise ratio.

The objective of the coronary artery evaluation is to convey clinically meaningful, consistent information about the presence, location, characterization and degree of atherosclerosis as well as to report on any coronary stenoses that are present. Coronary artery segments were evaluated using a Society of Cardiovascular Computed Tomography model [7].

Degrees of stenosis in invasive coronary angiography and CCTA were both divided into mild $(<50 \%)$, moderate $(50-69 \%)$, severe $(70-99 \%)$, total occlusion $(100 \%)[8]$

Invasive Coronary angiography was used as a reference standard within the following month of CCTA scan.

\section{Statistical analysis:}

Statistical analysis of the present study was conducted by SPSS V.20. Qualitative data was described using number and percent. Quantitative data was presented as mean and Standard Deviation (SD). Correlations between different variables was done using Spearman correlation coefficient. Agreement of PCI and CT for detection of lesions was expressed in sensitivity, specificity, positive predictive value, negative predictive value. The level of significance was adopted at $p<0.05$.

\section{Results}

Among 20 patients included in this study 8 $(40 \%)$ were males while $12(60 \%)$ were females. The age of the studied patients ranged from 41 to 66 years with a mean of $58.1 \pm 7.29$ years (Table 1 ).

Different risk factors for CAD were found in the studied patients including hypertension, diabetes mellitus, smoking and dyslipidemia as well as the laboratory findings (Table 2).

In (Table 3) calcium score was examined in the studied group, stratified by Zero Agatston units in 14 patients $(70 \%)$, minimal $(1-10)$ in 0 patients, mild (11-100) in 2 patients (10\%). Moderate (101$400)$ in 2 patients $(10 \%)$ and severe $(400-800$ Agatston units) in 2 patients (10\%). Patient with Calcium score more than 800 were excluded from this study.
Diagnosis of LAD mid-segment lesions by both CT and coronary angiography showed statistically significant strong positive correlation, $r=0.647$, $p=0.002$

Diagnosis of LAD distal lesions by both CT and coronary angiography showed statistically significant perfect correlation, $r=1.0, p=0.001$.

Correlation couldn't be performed of circumflex artery as the variable was constant by CT (Table 4).

Diagnosis of RCA in both mid and distal segment lesions by both $\mathrm{CT}$ and coronary angiography showed statistically significant perfect correlation, $r=1.0, p=0.001$ (Table 4).

Table (1): The demographic characteristics of the studied patients.

\begin{tabular}{ccc} 
Characteristics & $(\mathrm{n}=20)$ & $(\%)$ \\
\hline Age: & \multicolumn{2}{c}{$41-66$} \\
Range & \multicolumn{2}{c}{$58.10 \pm 7.29$} \\
Mean \pm S.D & \multicolumn{2}{c}{40.0} \\
Gender: & \multicolumn{2}{c}{60.0} \\
Male & 8 & 60.0 \\
Female & 12 &
\end{tabular}

Table (2): The risk factors, clinical, and laboratory characteristics of the studied patients.

\begin{tabular}{lcc}
\hline Characteristics & $(\mathrm{n}=20)$ & $(\%)$ \\
\hline Hypertension & 14 & 70.0 \\
Diabetes mellitus & 14 & 70.0 \\
Smoking & 8 & 40.0 \\
Dyslipidemia & 16 & 80.0 \\
S. creatinine level $(\mathrm{mg} / \mathrm{dl}):$ & \multicolumn{2}{c}{$1.02 \pm 0.19$} \\
$\quad$ Mean \pm S.D & \multicolumn{2}{|c}{$63.30 \pm 6.31$} \\
Ejection fraction \% & \multicolumn{2}{|c}{} \\
$\quad$ Mean \pm S.D
\end{tabular}

Table (3): Calcium score among the studied patients.

\begin{tabular}{llcc}
\hline Calcium score & & $(\mathrm{n}=20)$ & $(\%)$ \\
\hline Zero & 0 & 14 & 70 \\
Minimal & $1-10$ & 0 & 0 \\
Mild & $11-100$ & 2 & 10 \\
Moderate & $101-400$ & 2 & 10 \\
Severe & $>400$ & 2 & 10 \\
\hline
\end{tabular}


Table (4): Correlation between computed tomography and angiographic results among the studied patients.

\begin{tabular}{llc}
\hline Correlations & $r$ & $p$ \\
\hline LAD: & & \\
LAD mid-segment-CA \& CT & $0.647^{*}$ & $0.002^{*}$ \\
LAD distal-CA \& CT & 1.000 & $0.001^{*}$ \\
LCx: & & \\
LCx mid-segment-CA \& CT & - & - \\
LCx distal-CA \& CT & - & - \\
$R C A:$ & & \\
RCA mid-segment-CA \& CT & 1.000 & $0.001^{*}$ \\
RCA distal CA \& CT & 1.000 & $0.001^{*}$ \\
\hline
\end{tabular}

$r \quad$ : Spearman correlation.

: Statistically significant

CA : Coronary angiography other abbreviations as mentioned before.
Table (5): Correlation between all mid-segment lesion and distal segment lesions by computed tomography and angiographic among the study patients.

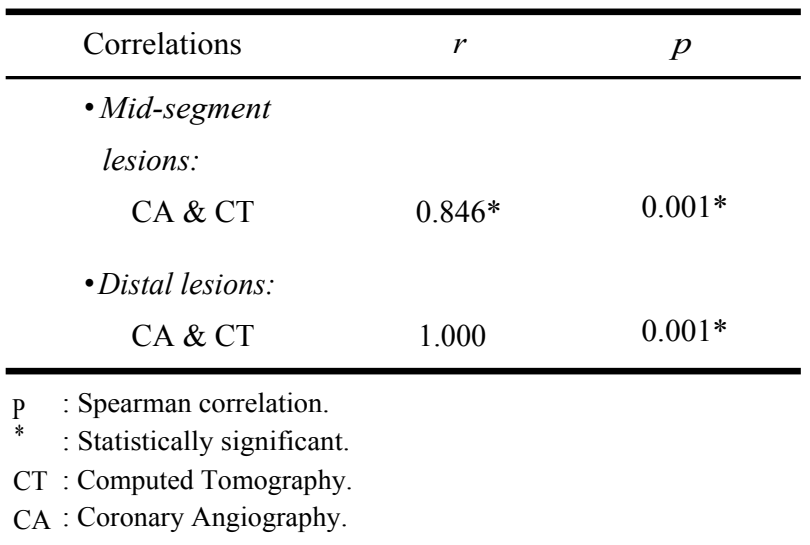

Table (6): Agreement sensitivity, specificity and diagnostic accuracy for computed tomography compared with angiography in detection of left anterior descending artery mid-segment.

\begin{tabular}{|c|c|c|c|c|c|c|c|}
\hline \multirow{2}{*}{$\begin{array}{l}\text { LAD mid- } \\
\text { segment lesions }\end{array}$} & \multicolumn{3}{|c|}{ Coronary angiography } & \multirow{2}{*}{ Sensitivity \% } & \multirow{2}{*}{ Specificity $\%$} & \multirow{2}{*}{ PPV\% } & \multirow{2}{*}{ NPV\% } \\
\hline & Positive & Negative & Total & & & & \\
\hline \multicolumn{8}{|l|}{$C T:$} \\
\hline Positive & 12 & 2 & 14 & & & & \\
\hline Negative & 0 & 6 & 6 & $100 \%$ & $75 \%$ & $85.7 \%$ & $100 \%$ \\
\hline Total & 12 & 8 & 20 & & & & \\
\hline
\end{tabular}

Table (7): Agreement sensitivity, specificity and diagnostic accuracy for computed tomography compared with angiography in detection of left anterior descending artery distal lesions.

\begin{tabular}{|c|c|c|c|c|c|c|c|}
\hline \multirow{2}{*}{$\begin{array}{l}\text { LAD distal } \\
\text { segment lesions }\end{array}$} & \multicolumn{3}{|c|}{ Coronary angiography } & \multirow{2}{*}{ Sensitivity $\%$} & \multirow{2}{*}{ Specificity $\%$} & \multirow{2}{*}{ PPV\% } & \multirow{2}{*}{ NPV\% } \\
\hline & Positive & Negative & Total & & & & \\
\hline \multicolumn{8}{|l|}{$C T:$} \\
\hline Positive & 2 & 0 & 2 & & & & \\
\hline Negative & 0 & 18 & 18 & $100 \%$ & $100 \%$ & $100 \%$ & $100 \%$ \\
\hline Total & 2 & 18 & 20 & & & & \\
\hline $\begin{array}{l}\text { PPV : Positive Prec } \\
\text { NPV : Negative Pre }\end{array}$ & $\begin{array}{l}\text { Value. } \\
\text { Value. }\end{array}$ & & & $\begin{array}{l}\text { LAD : Left anterio } \\
\text { CT : Computed T }\end{array}$ & $\begin{array}{l}\text { ending Artery. } \\
\text { raphy. }\end{array}$ & & \\
\hline
\end{tabular}

Table (8): Agreement sensitivity, specificity and diagnostic accuracy for computed tomography compared with angiography in detection of left circumflex artery mid-segment lesions.

\begin{tabular}{|c|c|c|c|c|c|c|c|}
\hline \multirow{2}{*}{$\begin{array}{l}\text { LCx mid-segment } \\
\text { lesions }\end{array}$} & \multicolumn{3}{|c|}{ Coronary angiography } & \multirow{2}{*}{ Sensitivity \% } & \multirow{2}{*}{ Specificity \% } & \multirow{2}{*}{ PPV\% } & \multirow{2}{*}{ NPV\% } \\
\hline & Positive & Negative & Total & & & & \\
\hline \multicolumn{8}{|l|}{$C T:$} \\
\hline Positive & 0 & 0 & 0 & & & & \\
\hline Negative & 2 & 18 & 20 & - & $100 \%$ & - & $90 \%$ \\
\hline Total & 2 & 18 & 20 & & & & \\
\hline
\end{tabular}


Table (9): Agreement sensitivity, specificity and diagnostic accuracy for ct compared with angiography in detection of left circumflex artery distal lesions.

\begin{tabular}{|c|c|c|c|c|c|c|c|}
\hline \multirow{2}{*}{$\begin{array}{l}\text { LCx distal } \\
\text { segment lesions }\end{array}$} & \multicolumn{3}{|c|}{ Coronary angiography } & \multirow{2}{*}{ Sensitivity \% } & \multirow{2}{*}{ Specificity \% } & \multirow{2}{*}{ PPV\% } & \multirow{2}{*}{ NPV\% } \\
\hline & Positive & Negative & Total & & & & \\
\hline \multicolumn{8}{|l|}{$C T:$} \\
\hline Positive & 0 & 0 & 0 & & & & \\
\hline Negative & 0 & 20 & 20 & - & $100 \%$ & - & $100 \%$ \\
\hline Total & 0 & 20 & 20 & & & & \\
\hline
\end{tabular}

Table (10): Agreement sensitivity, specificity and diagnostic accuracy for computed tomography compared with angiography in detection of right coronary artery mid-segment lesions.

\begin{tabular}{|c|c|c|c|c|c|c|c|}
\hline \multirow{2}{*}{$\begin{array}{l}\text { RCA Mid-segment } \\
\text { lesions }\end{array}$} & \multicolumn{3}{|c|}{ Coronary angiography } & \multirow{2}{*}{ Sensitivity \% } & \multirow{2}{*}{ Specificity \% } & \multirow{2}{*}{ PPV\% } & \multirow{2}{*}{ NPV\% } \\
\hline & Positive & Negative & Total & & & & \\
\hline \multicolumn{8}{|l|}{$C T:$} \\
\hline Positive & 4 & 0 & 4 & & & & \\
\hline Negative & 0 & 16 & 16 & $100 \%$ & $100 \%$ & $100 \%$ & $100 \%$ \\
\hline Total & 4 & 16 & 20 & & & & \\
\hline $\begin{array}{l}\text { PPV : Positive Predict } \\
\text { NPV : Negative Predic }\end{array}$ & $\begin{array}{l}\text { lue. } \\
\text { alue. }\end{array}$ & & & $\begin{array}{l}\text { RCA: Right Coror } \\
\text { CT : Computed T }\end{array}$ & $\begin{array}{l}\text { Artery. } \\
\text { graphy. }\end{array}$ & & \\
\hline
\end{tabular}

Table (11): Agreement sensitivity, specificity and diagnostic accuracy for computed tomography compared with angiography in detection of right coronary artery distal segment lesions.

\begin{tabular}{|c|c|c|c|c|c|c|c|}
\hline \multirow{2}{*}{$\begin{array}{l}\text { RCA Distal } \\
\text { segment lesions }\end{array}$} & \multicolumn{3}{|c|}{ Coronary angiography } & \multirow{2}{*}{ Sensitivity $\%$} & \multirow{2}{*}{ Specificity \% } & \multirow{2}{*}{ PPV\% } & \multirow{2}{*}{ NPV\% } \\
\hline & Positive & Negative & Total & & & & \\
\hline \multicolumn{8}{|l|}{$C T:$} \\
\hline Positive & 4 & 0 & 4 & & & & \\
\hline Negative & 1 & 15 & 16 & $80 \%$ & $100 \%$ & $100 \%$ & $93.7 \%$ \\
\hline Total & 5 & 15 & 20 & & & & \\
\hline $\begin{array}{l}\text { PPV : Positive Pre } \\
\text { NPV : Negative Pr }\end{array}$ & $\begin{array}{l}\text { Value. } \\
\text { e Value. }\end{array}$ & & & $\begin{array}{l}\text { RCA: Right Cor } \\
\text { CT : Computed }\end{array}$ & $\begin{array}{l}\text { Artery. } \\
\text { graphy. }\end{array}$ & & \\
\hline
\end{tabular}

Table (12): Agreement sensitivity, specificity and diagnostic accuracy for computed tomography compared with angiography in detection of mid-segment lesions in different vessels.

\begin{tabular}{|c|c|c|c|c|c|c|c|}
\hline \multirow{2}{*}{$\begin{array}{l}\text { Mid-segment } \\
\text { lesions }\end{array}$} & \multicolumn{3}{|c|}{ Coronary angiography } & \multirow{2}{*}{ Sensitivity $\%$} & \multirow{2}{*}{ Specificity \% } & \multirow{2}{*}{ PPV\% } & \multirow{2}{*}{ NPV\% } \\
\hline & Positive & Negative & Total & & & & \\
\hline \multicolumn{8}{|l|}{$C T:$} \\
\hline Positive & 16 & 2 & 18 & & & & \\
\hline Negative & 2 & 40 & 42 & $88.9 \%$ & $95.2 \%$ & $88.9 \%$ & $95.2 \%$ \\
\hline Total & 18 & 42 & 60 & & & & \\
\hline
\end{tabular}


Table (13): Agreement sensitivity, specificity and diagnostic accuracy for computed tomography compared with angiography in detection of distal segments lesions in different vessels.

\begin{tabular}{|c|c|c|c|c|c|c|c|}
\hline \multirow{2}{*}{$\begin{array}{l}\text { Distal segment } \\
\text { lesions }\end{array}$} & \multicolumn{3}{|c|}{ Coronary angiography } & \multirow{2}{*}{ Sensitivity $\%$} & \multirow{2}{*}{ Specificity \% } & \multirow{2}{*}{ PPV\% } & \multirow{2}{*}{ NPV\% } \\
\hline & Positive & Negative & Total & & & & \\
\hline \multicolumn{8}{|l|}{ CT: } \\
\hline Positive & 6 & 0 & 6 & & & & \\
\hline Negative & 1 & 53 & 54 & $85 \%$ & $100 \%$ & $100 \%$ & $98.1 \%$ \\
\hline Total & 7 & 53 & 60 & & & & \\
\hline
\end{tabular}

Table (14): Agreement sensitivity, specificity and accuracy for computed tomography compared with angiography in detection of all mid-segment and distal lesions in different vessels.

\begin{tabular}{|c|c|c|c|c|c|c|c|}
\hline \multirow{2}{*}{$\begin{array}{l}\text { All mid-segment and } \\
\text { distal segment lesions }\end{array}$} & \multicolumn{3}{|c|}{ Coronary angiography } & \multirow{2}{*}{ Sensitivity \% } & \multirow{2}{*}{ Specificity \% } & \multirow{2}{*}{ PPV\% } & \multirow{2}{*}{ NPV\% } \\
\hline & Positive & Negative & Total & & & & \\
\hline \multicolumn{8}{|l|}{ CT: } \\
\hline Positive & 22 & 2 & 24 & & & & \\
\hline Negative & 3 & 93 & 96 & $88 \%$ & $97.9 \%$ & $91.7 \%$ & $96.9 \%$ \\
\hline Total & 25 & 95 & 120 & & & & \\
\hline
\end{tabular}

\section{Discussion}

In the current study, mid and distal segments of coronary arteries were chosen because they are usually small in caliber especially distal segment (usually less than $1.5 \mathrm{~mm}$ ) and they are affected by cardiac motion on the contrary, the proximal segment is always away from the myocardium and usually larger in diameter so that it can be easily diagnosed by CTA.

The current study aimed to evaluate the diagnostic accuracy of CT coronary angiography for detecting coronary artery disease in mid and distal segment lesions using invasive coronary angiography as a reference standard.

Heart rate control is still essential even with the use of 320-row multi-slice CT scanner, not only to obtain good quality images, but also reducing the radiation dose to the patients. The slower heart rate $(<65 \mathrm{bpm})$ the better the temporal resolution and results in almost motion free images, it also permit the use of prospective ECG-gating that carries the advantage of much lower radiation dose compared to the previously routinely used retrospective gating method [9].

Giesler et al., [10] suggested that the duration of the diastolic phase with little cardiac motion is inversely related to the heart rate and then the heart rate is playing an important role in image quality during CTA.
In the current study, the pre-examined heart rate was evaluated and those with heart rate above $70 \mathrm{bpm}$ were given metopr 1 olol orally to obtain a slow stable heart rate. That was in agreement with what was reported by Raff et al., [3].

Based on arteries, lesions were more located at LAD then RCA followed by LCx and that agreed with Pilot study done by Dewey M. et al., [4] that found LAD lesions were more detected by CTA than other lesions.

Diagnosis of CAD in both mid-segment and distal segment lesions by both CT and Coronary Angiography showed statistically significant correlation in patient with > $50 \%$ lesions and $>-70 \%$ lesions in quantification of severity of stenosis with $p$-value 0.001 which agreed with Dewey et al., [12] . They stated that percent diameter stenosis determined with the use of CT showed good correlation with quantitative analysis of CCA. However, the previous findings disagreed with Yang, et al., [1]

The diagnostic accuracy of 320-slice CT angiography for detecting coronary artery stenosis in mid-segment lesions: Sensitivity was $90 \%$, specificity was $95 \%$, PPV was $90 \%$ and NPV was $95 \%$ at mid-segment level. That was in agreement with what was reported by Ong et al., [13] in midsegment lesions with a sensitivity of $88 \%$, a specificity of $96 \%$, a PPV of $85 \%$ and a NPV of $97 \%$. 
The diagnostic accuracy of 320-slice CT angiography for detecting coronary artery stenosis in distal segment lesions: Sensitivity was $85 \%$, specificity was $100 \%$, PPV was $100 \%$ and NPV was $98 \%$ at distal level. That was very close to Tiong Kiam Ong et al., [13] with a sensitivity of $90 \%$, a specificity of $100 \%$, a PPV of $97 \%$ and a NPV of $90 \%$.

The overall diagnostic accuracy of 320-slice $\mathrm{CT}$ angiography for detecting coronary artery stenosis in mid-segment and distal segment lesions: Sensitivity was $88 \%$, specificity was $98 \%$, PPV was $92 \%$ and NPV was $97 \%$. That was in disagreement with De Graaf et al., [11] that showed that sensitivity $100 \%$, specificity $88 \%$. But agreed with it in PPV 92\% and NPV 98\%. The specificity of CAD obstruction detection in this study was $98 \%$ (at both $50 \%$ and $70 \%$ stenosis thresholds). This specificity is higher than other noninvasive imaging modalities (e.g., stress echocardiogram, stress nuclear) [14].

\section{Limitations:}

\section{The current study had some limitations:}

- Individuals with heart rate greater than 65 beats per minute, calcium score more than 800 or a body mass index of greater than $35 \mathrm{~kg} / \mathrm{m}^{2}$ were excluded from the study.

- A comparison of coronary CT angiography and intravascular ultrasonography for coronary artery stenosis quantification was not performed.

- Small study number (only 20 patients).

- Single center study.

\section{Conclusion:}

The 320-slice CT angiography is a reliable tool and has high accuracy for detection of CAD in both mid and distal segment lesions. Importantly, the high NPV (97\%) firmly establishes CCTA as an effective noninvasive method to rule out obstructive coronary artery stenosis in patient with moderate pre-test probability.

\section{References}

1- YANG F.B., GUO W.L., SHENG M., et al.: Diagnostic accuracy of coronary angiography using 64-slice computed tomography in coronary artery disease. Saudi Med. J., October, 36 (10): 1156-62, 2015.

2- HOFFMANN U. and BAMBERG F.: Is computed tomography coronary angiography the most accurate and effective noninvasive imaging tool to evaluate patients with acute chest pain in the emergency department. Circ. Cardiovasc. Imaging May, 2 (3): 251-63, 2009.

3- GARCIA M.J., LESSICK J. and HOFFMANN M.H.: Accuracy of 16-row multidetector computed tomography for the assessment of coronary artery stenosis. JAMA July, 26; 296 (4): 403- 11, 2006.

4- DEWEY M., VAVERE A.L., ARBAB-ZADEH, et al.: Patient characteristics as predictors of image quality and diagnostic accuracy of MDCT compared with conventional coronary angiography for detecting coronary artery stenoses: CORE-64 Multicenter International Trial. AJR Am. J. Roentgenol. January, 194 (1): 93-102, 2010.

5- RAFF G.L., GALLAGHER M.J., O'NEILL W.W., et al.: Diagnostic accuracy of noninvasive coronary angiography using 64-slice spiral computed tomography. J. Am. Coll. Cardiol. August, 2; 46 (3): 552-7, 2005.

6- PONTONE G., BERTELLA E., MUSHTAQ S., et al.: Coronary artery disease: Diagnostic accuracy of CT coronary angiography a comparison of high and standard spatial resolution scanning. Radiology, 271 (3): 688-94, 2014.

7- LEIPSIC J., ABBARA S., ACHENBACH S., et al.: SCCT guidelines for the interpretation and reporting of coronary CT angiography: A report of the Society of Cardiovascular Computed Tomography Guidelines Committee. J. Cardiovasc. Comput. Tomogr., 8 (5): 342-58, 2014.

8- BUDOFF M.J., DOWE D., JOLLIS J.G., et al.: Diagnostic performance of 64 multidetectormrow coronary computed tomographic angiography formevaluation of coronary artery stenosis in individuals without known coronary artery disease: Results from the prospective multicenter ACCURACY (Assessment by Coronary Computed Tomographic Angiography of Individuals Undergoing Invasive Coronary Angiography) trial. J. Am. Coll. Cardiol., 52 (21): 1724-32, 2008.

9- GOLDMAN L.W.: Principles of CT: Multislice CT. J. Nucl. Med. Technol., 36 (2): 57-68, 2008.

10- GIESLER T., BAUM U., ROPERS D., et al.: Noninvasive visualization of coronary arteries using contrast-enhanced multidetector CT: Influence of heart rate on image quality and stenosis detection. A.J.R. Am. J. Roentgenol., 179 (4): 911-6, 2002.

11- De GRAAF F.R., SCHUIJF J.D., VAN VELZEN J.E., et al.: Diagnostic accuracy of 320-row multidetector computed tomography coronary angiography in the noninvasive evaluation of significant coronary artery disease. Eur. Heart J., 31 (15): 1908-15, 2010.

12- DEWEY M., ZIMMERMANN E., DEISSENRIEDER F., et al.: Noninvasive coronary angiography by 320 -row computed tomography with lower radiation exposure and maintained diagnostic accuracy: Comparison of results with cardiac catheterization in a head-to-head pilot investigation. Circulation, 120 (10): 867-75, 2009.

13- ONG T.K., CHIN S.P., LIEW C.K., et al.: Accuracy of 64-row multidetector computed tomography in detecting coronary artery disease in 134 symptomatic patients: Influence of calcification. Am. Heart J., 151 (6): 1323 6, 2006.

14- BUDOFF M.J., ACHENBACH S., BLUMENTHAL R.S., et al.: Assessment of coronary artery disease by cardiac computed tomography: A scientific statement from the American Heart Association Committee on Cardiovascular Imaging and Intervention, Council on Cardiovascular Radiology and Intervention, and Committee on Cardiac Imaging, Council on Clinical Cardiology. Circulation, 114 (16): 1761-91, 2006. 


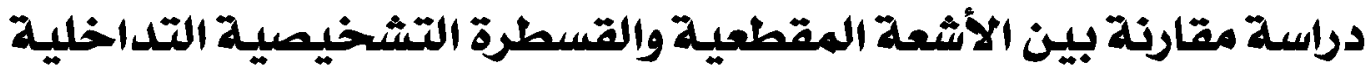

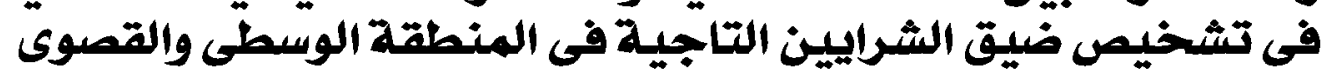

الهدف من هذه الدراسة هو تقييم دقة الأثعة المقطعية لتصوير الثرايين التاجية للكثف عن ضيق الثُريان التاجى باستخدام تصوير

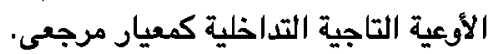

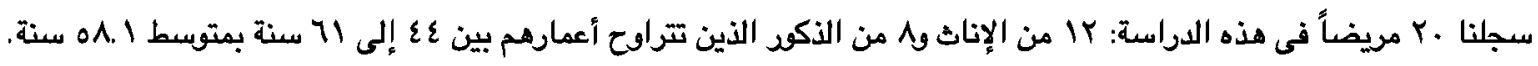
يثتسنى من الدراسة المرضى الذين سبق لهم تركيب دعامات بالاوعية التاجية أو سبق لهم عمل جراحة قلب مفتوح للاوعية التاجية، ويثسنى إنى أيضاً مرضى قصور الكلى أو الصوامل.

الاستتاج: تصوير الأوعية التاجية بواسطة الاشعة المقطعية هو أداة موثقية وذات دقة عالية الشكف عن ضيق الشرايين التاجية في كل

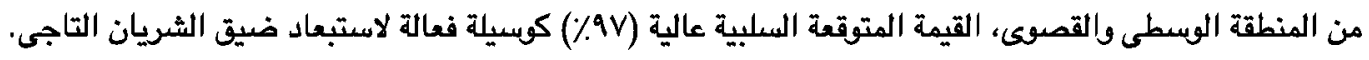

